\title{
IMPLANTAÇÃO DE PROGRAMAS DE MANEJO E PLANO DE GESTÃO AMBIENTAL EM PEQUENAS COMUNIDADES
}

\section{Implantation of Handling Programs and Plan of Environmental Administration in Small Communities}

\author{
Agostinho Paula Brito Cavalcanti \\ Professor Associado do Departamento de Geografia da Universidade Federal do Piauí (UFPI) .Pós-Doutor pelo Instituto \\ de Geociências e Ciências Exatas (IGCE) da Universidade Estadual Paulista "Júlio de Mesquita Filho" (UNESP) \\ Rio Claro/SP - Brasil \\ agos@ufpi.br
}

Artigo recebido para publicação em 25/03/2010 e aceito para publicação em 09/11/2010

RESUMO: O presente trabalho tem por objetivo o desenvolvimento de uma proposta para a implantação de programas de manejo e plano de gestão ambiental em pequenas comunidades, compondo um conjunto de procedimentos resultantes de métodos e técnicas de pesquisas. Os programas de manejo compreendem tópicos relativos aos setores de produção, a saber: infra-estrutura energética, viária, sanitária e de comunicação; silvicultura, extrativismo vegetal, agricultura e pecuária; aqüicultura; mineração, indústrias e atividades científicas, culturais, esportivas, turísticas, recreacionais e de serviços. Com relação ao plano de gestão ambiental, este deverá promover o desenvolvimento urbano e ordenamento dos serviços, abrangendo os setores de educação; saúde; saneamento; transporte; energia e urbanização, além das ações direcionadas ao potencial natural, abrangendo a proteção do patrimônio histórico, cultural e natural, ecoturismo; pesquisas; gerenciamento e fiscalização. Como etapa conclusiva percebe-se a falta de uma política de caráter integrado que oriente a utilização racional e a proteção dos recursos naturais e a não obediência da legislação ambiental.

Palavras-Chave: Geografia. Manejo. Gestão Ambiental.

ABSTRACT: The present work has for objective the development of a proposal for the implantation of handling programs and plan of environmental administration in small communities, composing a group of resulting procedures of methods and techniques of researches. The handling programs include topics relative production sections, to know: infrastructure energy, road, sanitary and communication; forestry, vegetation, agriculture and livestock; aquaculture; mining, you elaborate and activities inform, cultural, sporting, tourist, recreational services. Regarding the plan of environmental administration, this should promote the urban development and ordainment of the services, including the education sections; health; sanitation; transport; energy and urbanization, besides the actions addressed to the natural potential, including the protection of the patrimony historical, cultural and natural; ecotourism; researches; administration and supervision. As conclusive stage is noticed the lack of a character politics integrated that it guides the rational use and the protection of the natural resources and the not obedience of environmental legislation.

Keywords: Geography. Management. Environmental management. 


\section{INTRODUÇÃO}

O desenvolvimento sob a perspectiva de suas limitações e diversidades sócio-ambientais deve levar em consideração o potencial existente para diferentes empreendimentos econômicos e atividades extrativistas; necessidade de infra-estrutura básica; controle do uso e ocupação do solo e a proteção do patrimônio histórico e cultural, elementos essenciais na estruturação sócio-econômica local.

O processo de planejamento físico-territorial e ambiental e os programas de desenvolvimento terão de considerar as atividades produtivas, com a criação de novas áreas de ocupação e de serviços diversos e na multiplicação dos usuários e investidores. Neste sentido, os programas de manejo e o plano de gestão têm como objetivo a organização do espaço, incentivando a recuperação econômica e ecológica das iniciativas já existentes e o planejamento de novos investimentos de ocupação, procurando harmonizar políticas de meio ambiente e o desenvolvimento com a problemática ambiental diagnosticada.

Este trabalho propõe a implantação de programas de manejo e plano de gestão ambiental em pequenas comunidades, compondo um conjunto de procedimentos resultante de pesquisas para a identificação de opções para a solução dos problemas que conduzem à degradação dos recursos naturais e dos sistemas produtivos.

Através dos programas de manejo é possível compatibilizar a ação com a dinâmica natural de forma assegurar a implantação e o aperfeiçoamento das medidas necessárias para a execução das metas estabelecidas, devendo ser aplicadas gradualmente através de projetos integrados com a participação da comunidade, com as instituições governamentais e não governamentais e de consultorias técnico-científicas.

A gestão ambiental visa solucionar problemas ligados a infra-estrutura urbana e de serviços e ao potencial natural com a implantação de planos de apoio ao desenvolvimento comunitário.

\section{PROPOSTA PARA IMPLANTAÇÃO DE PRO- GRAMAS DE MANEJO}

De início faz-se necessário a realização de um trabalho de base junto às comunidades locais, demonstrando os resultados da presente pesquisa, indicando as principais potencialidades e limitações detectadas e exposição das alternativas encontradas. Silva apud Cavalcanti (1997) acredita que parte das comunidades restringe-se de tomar iniciativas de autogestão no que concerne às suas atividades produtivas, no planejamento adequado da utilização de recursos naturais e nas medidas de preservação ambiental.

A aceitação, sugestões e participação da comunidade serão fundamentais para a realização dos programas de manejo sendo contemplados tópicos relativos aos setores de produção.

A execução de qualquer infra-estrutura energética, viária, sanitária, de comunicação e outras, deverão ocorrer mediante as seguintes medidas de manejo: os cortes e aterros deverão ser executados considerando-se critérios e estruturas que garantam a estabilização do relevo; os sistemas de drenagem deverão ser dimensionados mediante a adoção de critérios hidrológicos compatíveis com as condições pluviométricas locais, garantindo a estabilidade à erosão hídrica; a recomposição da vegetação natural nas áreas desmatadas, mediante a utilização de espécies vegetais nativas adequadas; as áreas de importância histórica, artística e paisagística, devendo ser realizados estudos especiais para garantir sua proteção.

As atividades de silvicultura e extrativismo vegetal poderão ser desenvolvidas de acordo com as medidas de manejo a seguir: a remoção da cobertura vegetal com corte seletivo deverá ser efetuada de forma que não provoquem impactos por resíduos de qualquer natureza; o rendimento sustentado de espécies nativas, desde que só se faça a extração de espécimes que tenham atingido a maturidade; Extração de outras espécies vegetais para fins de alimentação, ornamental, artesanal e medicinal, desde que não se dê nas áreas de ocorrência de associações vegetais relevantes e que não inclua espécies raras ou ameaçadas de extinção.

As atividades de agricultura e pecuária poderão ser realizadas mediante a observância das seguintes medidas de manejo: Desmatamento e movimentos de terra só serão permitidos nas áreas previstas nos projetos de implantação e ampliação; Áreas abandonadas deverão ter a flora recomposta, mediante emprego diversificado de espécies nativas adequadas, perten- 
centes à mata original; Cultivo e criação de espécies nativas só serão permitidos quando se dominar seu ciclo biológico completo; Cultivo e criação de espécies exóticas deverão contar com sistemas de segurança, a fim de impedir sua fuga para o meio ambiente.

As atividades de aqüicultura poderão ser desenvolvidas levando-se em consideração as seguintes medidas de manejo: Obras civis, cortes e aterros, viveiros, barragens e outras instalações deverão ser executadas mediante a adoção de critérios e estruturas que garantam sua estabilidade; Implantação dos projetos em áreas de salinas ou desmatadas, evitando-se as áreas de ocorrência de associações vegetais relevantes e em áreas de importância para a reprodução e sobrevivência de espécies animais raras, endêmicas e/ou ameaçadas de extinção; Criação de espécies nativas só será permitida quando se dominar seu ciclo biológico completo (espécies retiradas do meio natural não poderão ser utilizadas como insumo para a atividade produtiva); Criação de espécies exóticas deverá contar com sistemas de segurança nos canais de escoamento ou outros locais, a fim de impedir sua fuga para o meio ambiente.

A atividade de mineração poderá ser desenvolvida de acordo com as seguintes medidas de manejo: Adoção de medidas de tratamento de efluentes, com seu lançamento em qualidade compatível com a bacia receptora; Execução de dispositivos hidráulicos, que asseguram a estabilidade à erosão dos pontos de lançamento e corpos receptores; Disposição de rejeitos em local adequado, sem implicar na contaminação dos solos, cursos e reservatórios de água; Recomposição de quaisquer áreas desmatadas, mediante emprego diversificado de espécies nativas adequadas, pertencentes à mata original.

As atividades industriais poderão ser adequadas mediante a observância das seguintes medidas de manejo: Instalações industriais que não comprometam a estabilidade do relevo; Instalações industriais com dispositivos adequados de tratamento de efluentes, permitindo lançamento com qualidade compatível com a bacia receptora; Drenagem das águas pluviais das instalações e vias de acesso efetuado por meio de estruturas hidráulicas adequadas; Utilização de equipamentos adequados para filtragem de emissões, não afetando as comunidades locais, fauna e flora.
As instalações e equipamentos necessários ao desenvolvimento de atividades científicas, culturais, esportivas, turísticas, recreacionais e de serviços, deverão ser implantadas segundo as seguintes medidas de manejo: Compatibilização das edificações e/ou equipamentos com as características naturais das unidades ambientais; Edificações e demais obras civis não interfiram na estabilização do relevo, com instalações adequadas para tratamento e lançamento de esgotos sanitários; Lançamento de efluentes e águas pluviais com estruturas hidráulicas convenientes, garantindo a estabilidade à erosão hídrica nos pontos de lançamento e nos corpos receptores; Obras civis realizadas com a máxima proteção da vegetação natural, com recomposição em áreas desmatadas por espécies vegetais nativas; Sistema de recolhimento e disposição de resíduos sólidos, não podendo provocar poluição edáfica e hídrica.

Para que essas medidas sejam efetivadas, torna-se necessária a alteração do quadro sóciopolítico através da revisão de conceitos referentes à posse da terra, apropriação e uso dos recursos naturais, referencial de qualidade de vida e cidadania.

De acordo com Lopes (1990) o planejamento é um sistema, cujos limites guardam relação com a amplitude de sua meta, consistindo em um ambiente vida/natureza, no qual se relacionam o homem e os locais e eventos naturais; o ambiente social/humano, no qual se estabelecem as principais interdependências grupais, em todos os níveis e o ambiente objeto/ tecnologia, no qual estão concentrados os objetos, os resultados materiais e intelectuais da mente humana.

Além dos programas de manejo da produção devem ser agrupadas as atividades que visem o ordenamento das intervenções, estando reunidos nos seguintes programas de manejo de apoio, definidos através de suas metas, ações e recursos básicos:

a) Pesquisas

- Metas: Agrupamento do conhecimento sobre os recursos naturais e características de seus visitantes, de forma a apoiar com dados, métodos e conceitos científicos de manejo.

- Ações: Estabelecimento de convênios com instituições para realização de programas cooperativos de estudos e pesquisas; 
Realização de estudos para subsídio aos projetos de recuperação vegetal e proteção ambiental; Aprofundamento de levantamentos florísticos, faunísticos e fitossociológicos; realização de pesquisas do perfil do usuário para ajuste da capacidade de suporte das áreas de visitação e trilhas; Acervo bibliográfico com material de pesquisas.

- Recursos básicos: Estabelecimento de parcerias com organizações públicas e privadas.

b) Manejo dos Recursos Naturais

- Metas: recuperação de áreas degradadas e restauração do ambiente natural.

- Ações: controle no aparecimento de espécies invasoras e eliminação de espécies exóticas, definidas em estudos e pesquisas; possibilidade de recuperação da vegetação e implantação de projetos de recuperação das áreas degradadas; implantação de projetos de contenção em áreas instáveis.

- Recursos básicos: aprofundamento dos levantamentos florísticos e geológicos.

c) Monitoramento

- Metas: acompanhamento da evolução e desenvolvimento dos recursos naturais.

- Ações: monitoramento das condições físicas e biológicas da evolução dos processos de recuperação natural e induzido; monitoramento da evolução da fauna, condições climáticas, recursos hídricos e qualidade ambiental.

- Recursos básicos: Estabelecimento de convênios com organizações públicas, privadas e não governamentais para as atividades de monitoramento.

d) Recreação e Lazer

- Metas: desenvolvimento de atividades recreativas e de lazer, de acordo com as aptidões e potencialidades das áreas definidas no zoneamento.

- Ações: adoção de medidas necessárias para segurança (sinalização, obras de contenção de deslizamentos de barreiras e passarelas); elaboração e implantação dos projetos das obras necessárias ao desenvolvimento do programa.

- Recursos básicos: estabelecimento de convênios com organizações públicas, privadas e não governamentais para as atividades de recreação e lazer.

e) Educação Ambiental

- Metas: percepção e compreensão sobre os recursos naturais, sócio-culturais, e econômicos, como fatores físicos e mentais imprescindíveis à qualidade de vida, aprimoramento humano da cidadania e da solidariedade; estímulo à utilização da área e seus recursos pelas escolas, organizações civis e instituições públicas e privadas; desenvolvimento de estudos técnicos, científicos, métodos e práticas de proteção e educação ambiental.

- Ações: promoção de atividades educativas e culturais para as comunidades, visando o desenvolvimento e aprimoramento do conhecimento e a interação com os recursos naturais; promoção de cursos de treinamento direcionados a comunidade local, com qualificação de agentes de proteção ambiental e grupos de defesa do meio ambiente; organização e apoio a eventos ecológicos e culturais destinados à comunidade; divulgação das potencialidades e limitações naturais para o desenvolvimento de estudos, métodos e práticas ambientais.

- Recursos básicos: alocação de recursos para implantação do programa através de convênios com organizações públicas e privadas.

f) Administração e Manutenção

- Metas: definição e implantação do Plano de Gestão, em consonância com os objetivos, zoneamento e normas; manutenção da integridade dos recursos naturais e infra-estruturas. 
- Ações: estabelecimento das formas e níveis de participação institucional e comunitária no planejamento e gestão das atividades; dotação de recursos humanos e materiais necessários para implantação do Plano de Gestão; implantação de uma política de alocação e captação de recursos; atualização dos programas de manejo.

- Recursos básicos: Alocação de recursos através de convênios com organizações públicas e privadas.

Nessa concepção, os elementos constituintes do presente programa de manejo, levaram em consideração as limitações ambientais e sua adequação às necessidades das comunidades, resultando na valorização dos recursos naturais e sócio-econômicos.

\section{PROPOSTAS PARA IMPLANTAÇÃO DO PLA- NO DE GESTÃO AMBIENTAL}

A gestão ambiental ocupa totalmente posição de destaque dentre as prioridades debatidas no âmbito das ciências ambientais, observando-se mudanças significativas no comportamento da sociedade.

Nos últimos anos o aproveitamento da legislação ambiental vem acarretando um maior controle sobre as atividades dos setores produtivos e de consumo, visando atender às exigências da proteção ambiental. Macedo (1994) propõe quatro ferramentas metodológicas básicas para a Gestão Ambiental Territorial, quais sejam, o Ordenamento territorial, o Plano para otimização do desempenho ambiental, o Sistema de gestão territorial e o Sistema da qualidade ambiental.

Para ser efetivo, qualquer plano de gestão deve ser preventivo ao invés de corretivo, visar o futuro, contabilizar as experiências do passado, para efetivamente proteger os recursos remanescentes e restaurar ou reabilitar as unidades ambientais. Deve identificar necessidades e problemas com base na análise dos recursos naturais, suas tendências, potencialidades de ação dos impactos e valores sócio-culturais.

Almeida et al (1993) salienta que o plano de gestão em nada resolverá as questões ambientais se o espaço não for entendido como uma instância social e não como mero apoio das atividades humanas, onde o espaço físico é o reflexo não apenas dos processos naturais, como também das contradições da sociedade, na medida em que são os interesses sócio-econômicos os determinantes das formas de apropriação e exploração do espaço.

Para Kumpera (1979) os métodos tradicionais de planejamento eram baseados na elaboração de um plano diretor "estático". Atualmente, é compreendido como um processo essencialmente dinâmico, ocorrendo mudanças em uma ou mais de suas características ao longo do tempo.

É de fundamental importância uma coordenação entre as agências governamentais (federais, estaduais e municipais) e não-governamentais, evitando que parceiros implantem ações contraditórias, comprometendo o patrimônio natural, econômico e social.

\section{PLANO DE GESTÃO AMBIENTAL: INFRA- ESTRUTURA URBANA E DE SERVIÇOS}

O plano de gestão ambiental deverá promover o desenvolvimento urbano e o ordenamento dos serviços, abrangendo os setores de Educação, Saúde, Saneamento, Transportes, Energia e Urbanização, além de ações direcionadas ao potencial natural, abrangendo a proteção do patrimônio histórico, cultural e natural, Ecoturismo, Pesquisas e Gerenciamento e Fiscalização:

$\mathrm{Na}$ educação deverá prevalecer a redução dos índices de analfabetismo infantil e adulto local, a introdução de conceitos de educação ambiental formal e informal, e a construção de escolas comunitárias, geridas pela população, com apoio das instituições governamentais ou não-governamentais, tendo como metas a alfabetização de todas as crianças na faixa etária de 7 a 14 anos e de alfabetizar a população adulta; implantação de uma rede escolar municipal, abrangendo os ensinos fundamental e médio; criação de serviço de assistência aos alunos (orientação e aperfeiçoamento pedagógico); elaboração de programas de cursos de capacitação profissional, elaboração de plano para integração da rede formal e informal de educação; reforma e ampliação de escolas, construção ou adaptação de novas escolas. 
Como estratégias para atingir estas metas, seria operacionalizar as escolas públicas estaduais e municipais existentes, equipando-as convenientemente e dotando-as de recursos humanos necessários ao ensino básico na alfabetização de crianças e adultos, a partir da capacitação e/ou reciclagem dos professores.

$\mathrm{Na}$ saúde a construção de postos de saúde favorecendo $o$ atendimento emergencial e contribuindo para a redução de doenças endêmicas através da dinâmica dos agentes de saúde e campanhas públicas, torna-se fundamental para o pleno desenvolvimento.

Como metas prioritárias para a melhoria da assistência médico-hospitalar, deverão ser ampliadas à capacidade de atendimento nos postos de saúde $\mathrm{e}$ a criação de serviços ambulatoriais nas localidades; ampliação do atendimento à gestante, pré-natal e imunizações; instalação de atividades de enfermagem de saúde pública com programas de visitas domiciliares; criação de postos rurais de atendimento médicoodontológico. Atualmente as práticas homeopáticas estão plenamente aceitas no tratamento de saúde, recorrendo-se as plantas medicinais e aos métodos naturais para cura de doenças.

Baseando-se na realidade e valores sócioculturais das comunidades, é necessária a inserção do tratamento de saúde efetuado através das plantas medicinais, como recursos mais acessíveis, dado o baixo nível de renda local. Sabe-se que este tratamento é feito de forma simples e barata, visto que a maioria da população não dispõe de recursos financeiros para uma assistência de saúde adequada.

Tendo como metas o atendimento da população residente e flutuante; formação de agentes de saúde; programas de assistência à infância e o acompanhamento de campanhas endêmicas implantadas pelo Estado e Municípios, a estratégia de operacionalização será através de projetos que envolva, além das edificações e equipamentos necessários, o treinamento de recursos humanos, que contribuirão para um atendimento mais direto às necessidades das comunidades costeiras.

Através de programas integrados com os setores de Educação e Saúde, visando o pleno aproveitamento dos recursos disponíveis, deveriam ser criados órgãos municipais de promoção social, compreendendo atendimento social direto à família, ao menor abandonado, mendigos, deficientes físicos, prostitutas, alcoólatras, etc.; capacitação profissional e educação informal de base (educação de adultos, formação de líderes e treinamento de pessoal voluntário); cultura (programação de cultura popular, teatro e cinema amador, clubes de leitura, conjuntos musicais, corais, folclores); esportes e recreação (atividades esportivas comunitárias, recreação para diferentes faixas etárias); habitação de interesse social (programa de atendimento às classes de baixa renda e marginalizados) $\mathrm{e}$ integração à vida em comunidade.

Com relação ao abastecimento e saneamento (água, esgoto e coleta de resíduos sólidos) deverão ser implantadas ações que têm por objetivo o atendimento às necessidades básicas da população residente, operacionalizando um sistema de distribuição e despoluição da água e implantação de um sistema de esgotamento sanitário, capazes de atender às necessidades da população residente e suporte à população flutuante, manutenção da limpeza nas localidades e através da Educação Ambiental alcançar uma sistemática de separação dos diferentes tipos de lixo e/ou seu devido aproveitamento.

As metas para atingir estes objetivos deverão estar direcionadas a implantação de sistemas de canalização de água entre os poços existentes e captação nos reservatórios de água; realização de ligações domiciliares visando o abastecimento de água; monitoramento da qualidade dos recursos hídricos existentes e manutenção permanente dos equipamentos; dotação dos núcleos urbanos de sistemas de esgotamento sanitário, atendendo as necessidades locais e a implantação de sistema de coleta diária de resíduos sólidos dos domicílios, logradouros públicos e praias.

Como estratégia para a operacionalização destas metas seria adotado um sistema de abastecimento de água a partir da exploração dos poços já implantados, promovendo sua manutenção, recolhimento de taxas e monitoramento periódico dos recursos hídricos existentes. O sistema de esgotamento sanitário poderá ser convencional ou alternativo, desde que atenda a todas as localidades, sem comprometer os sistemas de abastecimento existentes e o lençol freático. O sistema de coleta de lixo deverá existir a partir de uma definição dos locais destinados a disposição desse material, devendo os órgãos ambientais, em articulação com 
as prefeituras, apresentarem propostas compatíveis, locando esse aterro fora dos limites urbanos, devendo contemplar as possibilidades de separação de material reciclável e utilização de matéria orgânica como fonte de energia alternativa.

Os resíduos sólidos são considerados como importante insumo no processo produtivo, devendo ser recuperado através da coleta seletiva e reciclagem, promovido pelas prefeituras, setor privado e comunidade, responsáveis pela operacionalização dos sistemas de coleta, devendo-se incentivar programas de reciclagem que contemplem atividades de separação e entrega em postos de coleta.

A questão dos resíduos sólidos inclui a coleta, tratamento e disposição adequada de todos os subprodutos e produtos finais (lixo convencional ou tóxico), devendo atuar de modo a garantir que a quantidade de resíduos seja reduzida já nas fontes geradoras.

O estabelecimento de novas prioridades para a gestão de resíduos sólidos, implica uma mudança substancial nos processos de coleta e disposição, visando adotar um fluxo circular no qual a quantidade de resíduos reaproveitados seja maior que a quantidade a serem dispostos. Algumas alternativas poderiam ser implantadas, tais como:

1.No lugar da reciclagem, seria efetivada a reutilização, ou seja, antes de depositar os produtos em aterros sanitários, devese reaproveitar a energia presente nos resíduos;

2.Promover alterações no processo de produção, tendo em vista a utilização de menor quantidade necessária de energia e matéria-prima, gerando uma menor quantidade de resíduos;

3. Estimular o emprego de tecnologias limpas e de baixo desperdício;

4. No sistema de distribuição, as embalagens de transporte dos produtos sejam feitos com material reutilizável ou reciclável;

5.Promover mudanças nos hábitos de consumo, priorizando a compra de produtos que possam ser reciclados.

Estas alternativas exigem uma série de mudanças no comportamento da sociedade em todas as etapas, algumas ainda difíceis de alcançar.
Com relação aos transportes e construção de rodovias deverão ser implantadas vias de acesso adequadamente projetado, ligando as localidades as sedes municipais e a implantação de sistemas regulares de transporte que atenda ao deslocamento da população; tendo como meta a construção de estradas vicinais e concessão de linhas regulares de transporte intermunicipal. Como estratégias seriam viabilizados estudos que determinam a construção de vias compatíveis com a proteção dos valores ambientais existentes, não utilizando revestimento asfáltico e evitando a construção de pontes sobre as áreas inundáveis e/ou reservatórios de água.

O plano de gestão contemplará a elaboração de projetos para construção, recuperação e conservação das vias de acesso às localidades e a implantação de transportes alternativos visando o deslocamento da população e da produção de forma mais eficiente.

A implantação de sistema de energia que atenda as necessidades básicas da comunidade teria como meta o abastecimento com energia convencional ou não, abrangendo as residências, postos de saúde, maternidades, restaurantes, pousadas, pequenos comércios e logradouros públicos; tendo como estratégia a operacionalização de sistemas de energia alternativa, explorando as fontes eólica e solar, além da implantação de energia elétrica convencional.

A urbanização das localidades teria como objetivo proporcionar o desenvolvimento urbano ordenado, favorecendo a implantação do código de obras e posturas para os municípios com disposições mais restritivas, em consonância com o disposto na legislação vigente, tendo como meta o delineamento das ruas dos perímetros urbanos, licenciamento e cadastramento das construções e como estratégia a operacionalização do traçado urbano nas localidades.

No planejamento de pequenas comunidades segundo Ferrari (1979) três aspectos são fundamentais: o uso do solo urbano (zoneamento); circulação (sistema viário) e serviços públicos ou de utilidade pública, onde há uma prevalência dos problemas físico-territoriais, em detrimento dos aspectos econômico-sociais.

Deve-se levar em consideração que o planejamento visa resolver os problemas de uma sociedade, localizada em determinada área ou espaço, numa 
Implantação de programas de manejo e plano de gestão ambiental em pequenas comunidades Agostinho Paula Brito Cavalcanti

determinada época, surgindo então à necessidade do planejamento físico territorial, ou seja, a organização do espaço em que o homem exerce suas atividades, visando eliminar ou atenuar as distorções existentes decorrentes da evolução da sociedade.

Devido às interligações dos problemas que afetam as pequenas comunidades, propõe-se que o planejamento deva ser integral, envolvendo os proble- mas sociais, econômicos e físico-territoriais de forma interdependente. O Quadro 1 apresenta uma síntese do plano de gestão ambiental proposto para as atividades de infra-estrutura urbana e de serviços.

A partir do entendimento das pequenas comunidades como resultante das forças sociais, econômicas e ambientais e da reflexão crítica dos moradores, pode-se propor o denominado planejamen-

\begin{tabular}{|c|c|c|c|c|c|}
\hline $\begin{array}{c}\text { GESTÃO AMBIENTAL: } \\
\text { INFRA-ESTRUTURA } \\
\text { URBANA E DE } \\
\text { SERVIÇOS }\end{array}$ & OBJETIVOS & METAS & ESTRATÉGIA & $\begin{array}{c}\text { ADEQUAÇÃO DE USO } \\
\text { E OCUPAÇÃO }\end{array}$ & $\begin{array}{l}\text { PLANO DE } \\
\text { GESTÃO }\end{array}$ \\
\hline Educação & $\begin{array}{l}\text { Redução do } \\
\text { analfabetismo. } \\
\text { Educação } \\
\text { ambiental } \\
\text { Construção } \\
\text { de escola } \\
\text { comunitária. }\end{array}$ & $\begin{array}{l}\text { A } 1 \text { f a b e t i z a ç ã o } \\
\text { infantil. } \\
\text { Alfabetização adulta. }\end{array}$ & $\begin{array}{l}\text { Operacionalização } \\
\text { das escolas públicas; } \\
\text { Capacitação de } \\
\text { recursos humanos } \\
\text { em Educação }\end{array}$ & $\begin{array}{l}\text { Eficiência na educação } \\
\text { formal, informal e } \\
\text { ambiental. }\end{array}$ & $\begin{array}{l}\text { Elaboração de } \\
\text { programas educacionais. } \\
\text { Formação de agentes } \\
\text { multiplicadores. } \\
\text { Melhoria da infra- } \\
\text { estrutura. } \\
\text { Criação de conselhos. }\end{array}$ \\
\hline Saúde & $\begin{array}{l}\text { Construção de } \\
\text { postos de saúde. } \\
\text { Medicamento } \\
\text { domiciliar. }\end{array}$ & $\begin{array}{l}\text { Atendimento a } \\
\text { população residente } \\
\text { e flutuante. } \\
\text { Formação de agentes } \\
\text { de saúde. }\end{array}$ & $\begin{array}{l}\text { Operacionalização } \\
\text { de postos de saúde. } \\
\text { Capacitação de } \\
\text { recursos humanos } \\
\text { em saúde. }\end{array}$ & Eficiência na saúde. & $\begin{array}{l}\text { Elaboração de } \\
\text { programas de saúde. } \\
\text { Formação de agentes } \\
\text { multiplicadores. } \\
\text { Melhoria da infra- } \\
\text { estrutura de saúde. } \\
\text { Criação de conselhos de } \\
\text { saúde. }\end{array}$ \\
\hline $\begin{array}{l}\text { Abastecimento e } \\
\text { saneamento }\end{array}$ & $\begin{array}{l}\text { Distribuição de } \\
\text { água potável. } \\
\text { Implantação } \\
\text { de sistema de } \\
\text { esgoto sanitário } \\
\text { e coleta de } \\
\text { resíduos sólidos. }\end{array}$ & $\begin{array}{l}\text { Canalização de água } \\
\text { e esgoto. } \\
\text { Coleta diária e } \\
\text { seletiva de lixo }\end{array}$ & $\begin{array}{l}\text { Operacionalização } \\
\text { dos sistemas de } \\
\text { abastecimento, de } \\
\text { água e de coleta do } \\
\text { lixo. }\end{array}$ & $\begin{array}{l}\text { Eficiência e implantação } \\
\text { de abastecimento: esgoto } \\
\text { e resíduos sólidos }\end{array}$ & $\begin{array}{l}\text { Elaboração de } \\
\text { programas de } \\
\text { abastecimento e } \\
\text { saneamento básico. } \\
\text { Rede de água tratada. } \\
\text { Rede de esgoto. Aterro } \\
\text { sanitário e reciclagem } \\
\text { do lixo }\end{array}$ \\
\hline $\begin{array}{l}\text { Vias de acesso e } \\
\text { transportes }\end{array}$ & $\begin{array}{l}\text { Construção de } \\
\text { vias de acesso. } \\
\text { Implantação } \\
\text { de sistema de } \\
\text { transporte. }\end{array}$ & $\begin{array}{l}\text { Melhoria } \\
\text { das rodovias } \\
\text { pavimentadas ou } \\
\text { não. } \\
\text { Concessão de linha } \\
\text { regular entre as } \\
\text { localidades. }\end{array}$ & $\begin{array}{l}\text { Operacionalização } \\
\text { das vias de acesso às } \\
\text { localidades. } \\
\text { Estudos compatíveis } \\
\text { com a proteção } \\
\text { ambiental. }\end{array}$ & $\begin{array}{l}\text { Eficiência e implantação } \\
\text { de vias de comunicação e } \\
\text { transportes. }\end{array}$ & $\begin{array}{l}\text { Elaboração de planos } \\
\text { para construção, } \\
\text { recuperação e } \\
\text { conservação das vias de } \\
\text { acesso. Implantação de } \\
\text { transportes alternativos. }\end{array}$ \\
\hline Energia & $\begin{array}{l}\text { Implantação } \\
\text { de sistemas } \\
\text { de energia } \\
\text { convencional } \\
\text { e de sistemas } \\
\text { de energia } \\
\text { alternativa. } \\
\end{array}$ & $\begin{array}{l}\text { Atendimento as } \\
\text { localidades. } \\
\text { Melhoria das } \\
\text { condições sócio- } \\
\text { econômicas das } \\
\text { comunidades. }\end{array}$ & $\begin{array}{l}\text { Operacionalização } \\
\text { dos sistemas de } \\
\text { energia convencional } \\
\text { e alternativa; } \\
\text { Incentivo à } \\
\text { produção. }\end{array}$ & $\begin{array}{l}\text { Eficiência e implantação } \\
\text { de eletrificação } \\
\text { convencional e } \\
\text { alternativa. }\end{array}$ & $\begin{array}{l}\text { Ampliação da } \\
\text { distribuição da energia } \\
\text { elétrica. } \\
\text { Desenvolvimento } \\
\text { de programas para } \\
\text { utilização de energia } \\
\text { alternativa. }\end{array}$ \\
\hline Urbanização & & $\begin{array}{l}\text { Delineamento de } \\
\text { ruas. } \\
\text { Licenciamento } \\
\text { e cadastro das } \\
\text { construções. }\end{array}$ & $\begin{array}{l}\text { Ordenamento } \\
\text { urbano. } \\
\text { Capacitação e/ } \\
\text { ou reciclagem dos } \\
\text { recursos humanos. }\end{array}$ & $\begin{array}{l}\text { Regulamentação e } \\
\text { organização do uso e } \\
\text { ocupação do solo. }\end{array}$ & $\begin{array}{l}\text { Criação e implantação do } \\
\text { Plano Diretor nas áreas } \\
\text { de humana e agrária. }\end{array}$ \\
\hline
\end{tabular}

Quadro 1: Síntese do plano de gestão ambiental: infra-estrutura urbana e de serviços.

Fonte: CAVALCANTI (2000) 
to participativo, onde a coletividade deve dispor de mecanismos eficazes para influenciar a condução da máquina pública, ter acesso aos meios de comunicação e dispor de informações. A adoção desta prática passa pela democratização das decisões, de forma a permitir a participação da comunidade, garantindo o acesso á discussão dos problemas e direito de vigilância no cumprimento das ações.

\section{PLANO DE GESTÃo AMBIENTAL: PO- TENCIAL NATURAL}

As ações direcionadas ao potencial natural, abrangem a gestão do Patrimônio histórico e cultural, Patrimônio natural, Ecoturismo, Pesquisas e Gerenciamento e fiscalização, que serão descritas a seguir:

Para a proteção do patrimônio histórico e cultural devem-se observar a valorização das características locais, pelo incentivo a preservação de hábitos culturais, produções artísticas e estilos de comportamento, características da área, tendo como metas a elaboração e implantação de programas de preservação patrimonial e projetos para tombamento.

Para o setor cultural seriam promovidas feiras de artesanato com os produtos locais, confecção, bordados e comida regional e a promoção de atividades artísticas que valorizem o meio ambiente, através de peças com grupos de teatro locais, cordéis e festividades tradicionais. Seria incentivada a Educação Ambiental com a promoção de ações de capacitação como cursos, debates e seminários que integrem a população, com atuação na área de políticas sociais das instituições governamentais e não-governamentais.

O patrimônio natural deverá ser protegido de acordo com a legislação e valorizado visando à preservação de seu potencial, tendo como metas a elaboração e implantação de projetos de proteção, saneamento e controle ambiental.

As estratégias para a gestão do patrimônio natural passam pela operacionalização dos projetos e conscientização da população. Algumas alternativas poderiam ser implantadas, tais como:

1. Estímulo ao exercício da cidadania em defesa do patrimônio natural;

2. Transferência de conhecimento, formas de uso correto e tecnologias alternativas de uso e gestão dos recursos naturais;

3. Implantação de campanhas sobre medidas preventivas de controle ambiental;

4. Promover a Educação Ambiental no âmbito do ensino formal e informal;

5. Resgatar as potencialidades dos movimentos sociais e dos processos de mobilização e articulação das comunidades.

Deve-se observar que essas alternativas exigem mudanças substanciais no comportamento da sociedade e nas diretrizes do poder público.

Para as atividades de turismo ecológico (ecoturismo) devem ser fixadas regras para seu desenvolvimento local, estabelecendo parâmetros a serem observados, mediante a concessão de licenças e fiscalização. A implantação de obras de infra-estrutura turística provoca impactos ambientais negativos pelo estabelecimento ou ampliação de instalações, requerendo medidas atenuantes para minimizar esses impactos, tais como:

1. Estabelecimento do zoneamento e planos diretores dos municípios;

2. Adequação dos sistemas de abastecimento de água, tratamento de esgotos e resíduos sólidos;

3. Planejamento integrado dos acessos e dos núcleos urbanos;

4. Elaboração e implantação dos planos de manejo;

5. Estabelecimento de programas de Educação Ambiental;

6. Adequação da legislação ambiental.

As estratégias de ação seriam definidas de acordo com a elaboração e execução de programas de desenvolvimento do ecoturismo e da capacitação profissional da população local. Nos programas deve estar previstas ações como a proibição de acesso a zonas de significativo interesse ambiental e coletas de material; estabelecimento de limites da quantidade de turistas e informações sobre as formas de conduta. A capacitação deve possibilitar a participação da população, com adoção de medidas para o aprimoramento profissional e ingresso no mercado de trabalho.

As pesquisas seriam direcionadas ao conhecimento do potencial econômico, social e natural 
Implantação de programas de manejo e plano de gestão ambiental em pequenas comunidades Agostinho Paula Brito Cavalcanti

das localidades e ao monitoramento dos programas de manejo, tendo como metas a realização de estudos da potencialidade sócio-econômica e a implantação de ações voltadas para a utilização do potencial natural.

Para o potencial sócio-econômico seriam realizadas pesquisas sobre o perfil da população e dos possíveis usuários, com vistas a ajustar a capacidade de suporte das unidades ambientais. Para o potencial natural seriam efetivadas pesquisas de aprofundamento dos levantamentos da fauna, flora, clima e recursos minerais, visando uma avaliação da real condição desse potencial. O plano de gestão deverá prever a implantação de atividades economicamente viáveis e a ocupação e/ou qualificação da mão-de-obra em atividades produtivas.

Com relação ao gerenciamento e fiscalização deve-se prever sua estruturação em todos os níveis, bem como a regulamentação e controle do uso e ocupação do solo, tendo como metas a elaboração do código de posturas dos municípios e o cadastro das atividades produtivas.

Como estratégias para a operacionalização destas metas seriam criados conselhos municipais e organizações comunitárias, condicionando a população a torná-la responsável pela segurança e integridade ambiental e a elaboração e execução e fiscalização permanente, como os de ordenação da ocupação urbana; avaliação dos riscos ambientais; licenciamento

\begin{tabular}{|c|c|c|c|c|c|}
\hline $\begin{array}{c}\text { GESTÃO } \\
\text { AMBIENTAL: } \\
\text { POTENCIAL } \\
\text { NATURAL } \\
\end{array}$ & OBJETIVOS & METAS & ESTRATÉGIA & $\begin{array}{c}\text { ADEQUAÇÃO } \\
\text { DE USO E } \\
\text { OCUPAÇÃO }\end{array}$ & $\begin{array}{l}\text { PLANO DE } \\
\text { GESTÃO }\end{array}$ \\
\hline $\begin{array}{l}\text { Patrimônio } \\
\text { histórico e } \\
\text { cultural }\end{array}$ & $\begin{array}{l}\text { Proteção do } \\
\text { patrimônio histórico e } \\
\text { natural. } \\
\text { Valorização das } \\
\text { características locais. }\end{array}$ & $\begin{array}{l}\text { Elaboração de programas } \\
\text { de proteção do patrimônio } \\
\text { paisagístico, histórico e } \\
\text { cultural. }\end{array}$ & $\begin{array}{l}\text { Operacionalização de } \\
\text { projetos para proteção } \\
\text { do patrimônio } \\
\text { histórico e cultural. } \\
\text { Conscientização da } \\
\text { população. }\end{array}$ & $\begin{array}{l}\text { Eficiência na } \\
\text { proteção do } \\
\text { patrimônio } \\
\text { histórico cultural. }\end{array}$ & $\begin{array}{l}\text { Elaboração de programas de } \\
\text { Educação Ambiental. } \\
\text { Implantação ou recuperação de } \\
\text { áreas protegidas. }\end{array}$ \\
\hline $\begin{array}{l}\text { Patrimônio } \\
\text { natural }\end{array}$ & $\begin{array}{l}\text { Proteção do } \\
\text { patrimônio natural. } \\
\text { Valorização do } \\
\text { potencial natural local. }\end{array}$ & $\begin{array}{l}\text { Elaboração e implantação } \\
\text { de projetos de proteção } \\
\text { ambiental. } \\
\text { Elaboração de projetos } \\
\text { de saneamento e controle } \\
\text { ambiental. }\end{array}$ & $\begin{array}{l}\text { Operacionalização de } \\
\text { projetos para proteção } \\
\text { do patrimônio natural. } \\
\text { Conscientização da } \\
\text { população. }\end{array}$ & $\begin{array}{l}\text { Eficiência na } \\
\text { proteção do } \\
\text { patrimônio natural. }\end{array}$ & $\begin{array}{l}\text { Elaboração de programas de } \\
\text { Educação Ambiental. } \\
\text { Implantação ou recuperação } \\
\text { de áreas protegidas. }\end{array}$ \\
\hline Ecoturismo & $\begin{array}{l}\text { Desenvolvimento do } \\
\text { potencial ecoturístico. } \\
\text { Implantação de obras } \\
\text { de infra-estrutura } \\
\text { turística. }\end{array}$ & $\begin{array}{l}\text { Divulgação e valorização } \\
\text { do turismo ecológico. } \\
\text { Elaboração de planos } \\
\text { para construção ou } \\
\text { recuperação da infra- } \\
\text { estrutura. }\end{array}$ & $\begin{array}{l}\text { Elaboração e } \\
\text { execução de } \\
\text { programas de } \\
\text { desenvolvimento do } \\
\text { ecoturismo. } \\
\text { Capacitação } \\
\text { profissional da } \\
\text { população local. }\end{array}$ & $\begin{array}{l}\text { Ordenamento do } \\
\text { ecoturismo. }\end{array}$ & $\begin{array}{l}\text { Elaboração de programas para } \\
\text { as atividades ecoturísticas. } \\
\text { Divulgação do potencial } \\
\text { ecoturístico. }\end{array}$ \\
\hline Pesquisas & $\begin{array}{l}\text { Pesquisas sobre o } \\
\text { potencial econômico, } \\
\text { social e natural. } \\
\text { Monitoramento dos } \\
\text { programas. }\end{array}$ & $\begin{array}{l}\text { Realização de estudos da } \\
\text { potencialidade sócio- } \\
\text { econômica. } \\
\text { Implantação de ações } \\
\text { voltadas para a utilização } \\
\text { do potencial natural. }\end{array}$ & $\begin{array}{l}\text { Geração de emprego } \\
\text { e renda. } \\
\text { Implantação de } \\
\text { projetos e pesquisas } \\
\text { setoriais. }\end{array}$ & $\begin{array}{l}\text { Eficiência das } \\
\text { pesquisas. }\end{array}$ & $\begin{array}{l}\text { Ocupação e/ou qualificação } \\
\text { da mão-de-obra em atividades } \\
\text { produtivas. Implantação de } \\
\text { atividades economicamente } \\
\text { viáveis. }\end{array}$ \\
\hline $\begin{array}{l}\text { Gerenciamento } \\
\text { e fiscalização }\end{array}$ & $\begin{array}{l}\text { Estruturação do } \\
\text { gerenciamento e } \\
\text { fiscalização em todos } \\
\text { os níveis. } \\
\text { Regulamentação e } \\
\text { controle do uso e } \\
\text { ocupação do solo. }\end{array}$ & $\begin{array}{l}\text { Elaboração do código de } \\
\text { posturas nos municípios. } \\
\text { Cadastro das atividades } \\
\text { produtivas. }\end{array}$ & $\begin{array}{l}\text { Criação de conselhos } \\
\text { e organização } \\
\text { comunitária. } \\
\text { Elaboração de } \\
\text { programas de } \\
\text { gerenciamento } \\
\text { e fiscalização } \\
\text { permanente. }\end{array}$ & $\begin{array}{l}\text { Eficiência no } \\
\text { gerenciamento e } \\
\text { fiscalização das } \\
\text { atividades. }\end{array}$ & $\begin{array}{l}\text { Viabilização da organização } \\
\text { comunitaria. } \\
\text { Gerenciamento e fiscalização } \\
\text { do poder público com } \\
\text { participação da comunidade. }\end{array}$ \\
\hline
\end{tabular}

Quadro 2: Síntese do plano de gestão ambiental: potencial natural.

Fonte: CAVALCANTI (2000) 
e fiscalização do uso e ocupação do solo. O Quadro 2 apresenta uma síntese do plano de gestão ambiental proposto para as atividades do potencial natural.

A gestão inclui o gerenciamento e fiscalização do poder público com participação das comunidades locais e a viabilização e criação de organizações comunitária e associações de classe.

\section{CONCLUSÕES}

Percebe-se a falta de uma política de caráter integrado que oriente a utilização racional e a proteção dos recursos naturais, já que se subdivide em vários organismos, resultando na proliferação de entidades e órgãos com atribuições sobrepostas, ações setorizadas ou mesmo individualizadas, levando ao fracionamento e isolamento.

Deve-se priorizar a articulação das diferentes esferas administrativas com a participação da comunidade para a proteção ambiental, defesa do patrimônio e bens culturais, com a implantação de programas voltados para a ampliação da conscientização popular, indicando meios, instrumentos e mecanismos adequados para a proteção dos recursos naturais e sócio-econômicos.

Deve-se efetuar o levantamento e análise da legislação aplicável aos recursos naturais, com avaliação de superposições ou conflitos de competência e desenvolvidos estudos que recomendem procedimentos necessários ao aperfeiçoamento da legislação ambiental.

\section{REFERÊNCIAS}

ALMEIDA, J. R. et al. Planejamento Ambiental. Rio de Janeiro: Thex Editora/Biblioteca Estácio de Sá, 1993.

CAVALCANTI, A. P. B. Desenvolvimento Sustentável e Planejamento: Bases teóricas e conceituais. Fortaleza: Editora da UFC, 1997.

Impactos e condições ambientais da zona costeira do Estado do Piauí. 2000. Número de folhas. Tese (Doutorado em Geografia) - Instituto de Geociências e Ciências Exatas (IGCE), UNESP/ Rio Claro, São Paulo, 2000.
FERRARI, C. Curso de Planejamento Municipal Integrado. São Paulo: Livraria Pioneira Editora, 1979.

KUMPERA, V. Interpretação Sistêmica do Planejamento. São Paulo. Livraria Nobel S.A., 1979.

LOPES, C. T. G. Planejamento, Estado e Crescimento. São Paulo: Livraria Pioneira Editora, 1990.

MACEDO, R. K. Gestão Ambiental. Rio de Janeiro: ABES/AIDIS, 1994. 